\title{
VARIETIES OF SELF-APPREHENSION
}

\author{
Anna Giustina (Institut Jean Nicod) \\ Forthcoming in Marc Borner, Manfred Frank, and Kenneth Williford (eds.), \\ Senses of Self. Approaches to Pre-Reflective Self-Awareness
}

The Brentanian idea that every state of consciousness involves a consciousness or awareness of itself (Brentano 1874), which has been a central tenet of the phenomenological school, is a current topic in contemporary philosophical debates about consciousness and subjectivity, both in the continental and the analytic tradition. Typically, the self-awareness that accompanies every state of consciousness is characterized as pre-reflective. Most theorists of pre-reflective self-awareness seem to converge on a negative characterization: pre-reflective self-awareness is not a kind of reflective awareness. Whereas reflective self-awareness is attentive and descriptive, pre-reflective self-awareness is non-attentive and non-descriptive.

This paper aims to show that the reflective/pre-reflective dichotomy overlooks a finergrained distinction. The first part is devoted to arguing that the typical use of the adjective 'prereflective' conflates two properties (non-attentiveness and non-descriptiveness), which are in fact separable. Accordingly, not only can there be non-descriptive and non-attentive self-consciousness (i.e. pre-reflective self-awareness), but also non-descriptive but attentive self-consciousness. I call the latter primitive introspection. The second part of the paper is devoted to arguing that, whereas both prereflective self-awareness and primitive introspection enable the subject to apprehend the phenomenology of their experience, the kind of apprehension each allows for is different. By analyzing the notion of apprehension in terms of information acquisition and personal-level availability of information, it is proposed that, although both pre-reflective self-awareness and primitive introspection allow for acquisition of the maximal amount of information about the experience, only primitive introspection makes all such information personal-level available.

\section{VARIETIES OF NON-DESCRIPTIVE SELF-AWARENESS}

\subsection{Pre-reflective self-awareness: a standard characterization}

The idea that, for any mental state to be conscious, its subject must somehow be aware of it traces back to Aristotle (Caston 2002); it was advocated by Descartes (Dewalque 2018) and explicitly professed by Locke (Kriegel 2018: 23); but, arguably, it is Franz Brentano's (1874) endorsement of this idea that has conferred on it its central place in phenomenology and contemporary philosophy of mind. ${ }^{1}$

In recent analytic philosophy, the idea has sometimes been spelled out in terms of inner sense or higher-order representation: in order for a mental state to be conscious, it must be the

\footnotetext{
1 This idea has been criticized by reductive (first-order) representationalists, such as Fred Dretske (1995) and Michael Tye (1995), who maintain that for a mental state to be conscious it suffices that it represents something. Arguing against such criticisms falls out of the scope of this paper (there is, however, a huge literature against reductive representationalism. See e.g. Block 1995, Kriegel 2002, Chalmers 2004, and Siewert 2004). Here I simply assume that the principle that a mental state can only be conscious if the subject is aware of it is true. For a positive argument in support of the principle see Kriegel (2019).
} 
object of a distinct (meta-representational) quasi-perceptual state (Armstrong 1968; Lycan 1996) or higher-order thought (Rosenthal 1997). Many of those who share the Brentanian intuition but reject its higher-order representation development, have fleshed it out through the notion of prereflective self-awareness. Though labeled variously by different theorists and notwithstanding important theoretical dissimilarities among its proponents, the notion of pre-reflective selfawareness unites philosophers belonging to traditions as different as phenomenology, continental, and analytic philosophy.;

For one thing, differently from higher-order representation theorists, proponents of prereflective self-awareness maintain that a mental state is conscious not in virtue of being the object of awareness of another, distinct mental state, but rather in virtue of being self-aware (i.e. aware of itself): it is one and the same state that constitutes an awareness of worldly objects and of itself. Brentano (1874: 98) explains this in terms of secondary (vs. primary) object. any conscious mental act takes a worldly entity as its primary object and itself as a secondary object. When you hear a sound, on Brentano's view, by one and the same mental act (i.e. the act of hearing), you are aware both of the sound (which is the primary object of your mental act) and of your hearing of the sound (which is its secondary object). The latter kind of awareness (what Brentano calls 'inner perception') is prereflective in that it is non-observational (it is distinct from what Brentano calls 'inner observation'). Observational (i.e. attentive and inquisitive) awareness can only be directed to primary objects, whereas non-observational awareness can be directed to secondary objects and indeed accompanies every mental act. Like Brentano, several exponents of the phenomenological tradition maintained that mental acts are always accompanied by a non-observational, prereflective inner awareness. Contra Brentano, however, they argued that such awareness is not directed at itself as an object (it is awareness of oneself as a subject rather than as an object): it is a non-objectiffing inner awareness (see e.g. Husserl 2008, Sartre 1936). Contemporary analytic philosophers who argue that conscious experiences inherently involve (pre-reflective) selfawareness sometimes spell it out in terms of self-representation: an experience is conscious in virtue of representing itself in the right way (Kriegel 2009b; see also Kriegel and Williford 2006).

Pre-reflective self-awareness is typically characterized negatively, by contraposition with reflective self-awareness, which is often claimed to display the following set of features: it is mediated (i.e. indirect: there is something - a representation, an inferential process, a causal process, etc.mediating between the awareness and its object), relational (it implies at least two distinct mental states, that are contingently related to each other), explicit, objectifying, observational, attentive, conceptual (it involves the deployment of some concepts), and propositional in form. Accordingly, pre-reflective self-awareness is immediate, non-relational or intrinsic, implicit, non-objectifying, non-observational, non-attentive, nonconceptual, and non-propositional. ${ }^{4}$

\footnotetext{
2 As for phenomenology see e.g. Husserl (1983; 1991), Sartre (1936; 1943), Merleau-Ponty (1976), and Lévinas (1999). As for continental philosophy see e.g. the so-called Heidelberg School: Henrich (1970; 1982), Frank (1986; 1991), Cramer (1974), Pothast (1971); see Zahavi (1999; 2007) for a treatment of the notion of pre-reflective self-awareness in the Heidelberg School. As for analytic philosophy see e.g. Goldman (1970), Zahavi (1999; 2005), Horgan, Tienson, and Graham (2006), Horgan and Kriegel (2007), Kriegel (2009a; 2009b), Gallagher (2005), Williford (2006; 2015).

${ }^{3}$ I am not going to argue for the existence of pre-reflective self-awareness: by relying on the wide literature on it (some of which just cited in fn. 2), I simply take it for granted here.

${ }^{4}$ Although not all theorists agree that pre-reflective self-awareness has all these features, most of them do and all of them take it to have most of these features. In a slogan: most believe all and all believe most (Uriah Kriegel, personal communication, quoting Terry Horgan, personal communication).
} 
Although there is no general agreement as to how these features should be characterized (the characterization of explicit vs. implicit, for example, strikes me as particularly thorny), or as to whether pre-reflective self-awareness really has all these features, ${ }^{5}$ there does seem to be general agreement at least on the following. Reflective self-awareness is attentive and descriptive. It is attentive in that it requires the subject's drawing their attention to the experience it is an awareness of. For instance, reflective awareness of your gustatory experience of whisky requires you to attend to your whisky-taste experience. Plausibly, what is at issue here is conscious and voluntary attention. Some psychologists have argued that attending to something does not require being aware of it. ${ }^{6}$ Regardless of whether unconscious attention is psychologically real, philosophers interested in reflective self-awareness surely should take it to involve conscious attention, i.e. attention to the experience that implies an awareness of it. Moreover, in reflective self-awareness, attention is actively drawn to or kept focused on the experience, rather than grabbed by the experience independently of the subject's will. In this sense, it is voluntary: it requires an effort and an act of will on the part of the subject. So, the kind of attention involved in your being reflectively aware of your whisky-taste experience implies that you are aware of that experience and that you voluntarily and actively draw or keep your attention focused on it. Reflective awareness is descriptive in that it involves a cognitive activity on the part of the subject, consisting in classifying the relevant experience (i.e. somehow recognizing it as an instance of a known experience type), or applying some previously possessed concepts to it, ${ }^{7}$ aimed at forming a thought (with propositional content) about it. When you are reflectively aware of your whisky-taste experience, you apply some (more or less fine-grained) concepts. This enables you to form a number of thoughts about your experience, such as "this taste is strong", or "this tastes peaty", or "this tastes orangy-cakey".

Pre-reflective self-awareness, on the other hand, is non-attentive and non-descriptive. It is nonattentive in that it requires that the subject does not attend to the relevant experience-attention needs be directed elsewhere. Accordingly, you are pre-reflectively aware of your whisky-taste experience only when something else-some object in your environment, some other experience of yours, or the object of your experience, i.e. the whisky, rather than the experience itself-occupies the focus of your attention. It is non-descriptive in that it is free of any conceptualization or classification and thereby does not have the propositional form of a thought or a judgment.

What all pre-reflective self-awareness theorists seem to take for granted is, at the very least, that attentiveness and descriptiveness form a sort of package deal. The outcome is, as it were, a Manichean dichotomy. Attentive and descriptive (reflective) awareness on the one hand, nonattentive and non-descriptive (pre-reflective) awareness, on the other. I believe that this dichotomy is misguided because it offers too coarse-grained options. As it will emerge throughout this section, closer analysis suggests that the package may be split, opening up for further, finer-grained options.

\footnotetext{
${ }^{5}$ Kriegel (2009b: 105-106), for instance, argues that pre-reflective self-awareness is objectifying, since it is intentionally directed toward itself - it is an awareness of itself.

${ }^{6}$ Kentridge, Heywood, and Weiskrantz (1999), for instance, argue that blindsight patients may visually attend to objects in the blind area of their visual field.

${ }^{7}$ I take a concept $\mathrm{C}$ to be a mental representation that enables one to (i) distinguish Cs from non-Cs and (ii) recognize a $\mathrm{C}$ as a $\mathrm{C}$ (that is, as an instance of type $\mathrm{C}$ ).
} 


\subsection{The ambiguity of 'pre-reflective': unveiling a new region of the logical space}

As noted, typically, pre-reflective self-awareness is characterized as a kind of awareness which is non-attentive and non-descriptive. Brentano, as we saw, sharply distinguishes inner perception from inner observation, where the latter does, and the former does not, involve attention toward the mental act it is an awareness of. Phenomenologists insist that pre-reflective self-awareness is non-objectifying, which implies, at the very least, that it does not take itself as an object of attention. Contemporary analytic philosophers also characterize pre-reflective self-awareness as non-attentive. Uriah Kriegel (2009b: 47-53 and ibid. Ch. 5), for example, fleshes it out in terms of peripheral (vs. focal) inner awareness, where the focal/peripheral distinction tracks one's attentional resource distribution: what is attended to occupies the focus of one's attention, whereas what is unattended recedes to the periphery of one's phenomenal field.

The general assumption that attentiveness is always accompanied by descriptiveness in inner awareness may be justified by the fact that, quite often, the reason why we attend to our own experience is that we want to investigate it, know more about it, grasp the details of its phenomenology, or describe it to ourselves or to others. Arguably, when we so attend to our own experiences, we introspect them. Such introspective activity involves a reflective kind of inner awareness: it involves attending to one's own experience and concomitantly describing (i.e. forming thoughts or judgments about) it.

However, although descriptiveness often accompanies attentiveness in self-awareness, it does not do so necessarily, or so I contend. Indeed, there may be, and there at least sometimes is, a kind of self-awareness which is attentive but not descriptive. To be sure, prima facie, descriptiveness requires attentiveness: in order for you to be able to describe (actively form thoughts and judgments about) your current experience, you need, first, draw your attention to it. For instance, to describe your whisky-taste experience as 'orangy-cakey', you need first draw your attention to your taste experience. However, the converse does not hold: attentiveness does not imply descriptiveness. You may merely attend to your current experience, without classifying it, or applying concepts to it, or forming any judgment about it (Giustina forthcoming). You may well attend to your whisky-taste experience without also judging that the experience you are having is 'orangy-cakey', 'peaty', or 'strong'. Indeed, you may attend to your experience without classifying it as an instance of any previously encountered experience type. If so, in that case you instantiate a kind of self-awareness which is attentive but not descriptive. I call this non-descriptive but attentive kind of self-awareness primitive introspection. It is 'primitive' in that it is prior to and independent of any classification, conceptualization, or judgment. It is 'introspective' in that it involves the drawing of one's attention toward one's own current experience. ${ }^{8}$

My proposal, then, is that the notion of 'pre-reflective self-awareness' is, in a sense, ambiguous. Such ambiguity arises from the conflation of two features that are, in fact, separable: non-attentiveness and non-descriptiveness. Accordingly, there are at least two ways in which selfawareness may be 'pre-reflective': by being non-attentive and by being non-descriptive. Such a distinction unveils new regions of the logical space around self-awareness. Besides (i) what has traditionally been called pre-reflective self-awareness, which is both non-attentive and non-descriptive, and

\footnotetext{
8 The link between attention involvement and the "introspection" label may sound arbitrary; however, to be sure, psychological phenomena rather than terminology is the core issue here-a variety of different labels may be equally satisfactory. Relatedly and incidentally, since what has traditionally been called reflective self-awareness involves attention to the experience, it may legitimately be called, in my terminology, reflective introspection.
} 
(ii) reflective self-awareness (or reflective introspection'), which is attentive and descriptive, there is (iii) a kind of self-awareness which is attentive but non-descriptive-what I have called primitive introspection.

Above I suggested that, whereas attentiveness does not imply descriptiveness, the converse does not seem to hold: forming a judgment about one's own experience requires one's drawing one's attention toward it. Some, however, might want to challenge this claim and argue, from the separability of attentiveness and descriptiveness, for the existence of (iv) a kind of self-awareness which is descriptive but non-attentive. Indeed, the separability of attentiveness and descriptiveness (and of non-attentiveness and non-descriptiveness) does open, at the very least, the logical possibility of non-attentive descriptive self-consciousness. Whether such kind of self-consciousness is also psychologically real is a question that would require separate treatment, but which I am not going to address here. ${ }^{10}$

What I am mainly interested in, here, are the varieties of non-descriptive self-consciousness which emerge from the acknowledgment of the separability between attentiveness and descriptiveness. Particularly, I want to defend the idea that, besides pre-reflective self-awareness in the strict sense (i.e. the traditional notion of non-descriptive and non-attentive self-consciousness), there is another kind of non-descriptive self-awareness which is attentive, namely primitive introspection. In the next section I am going to provide some reasons for thinking that primitive introspection is a psychologically real phenomenon. Table 1 is a summary of the logical space around the notion of self-awareness, which emerges from the separability of attentiveness and descriptiveness (as well as of non-attentiveness and non-descriptiveness).

\begin{tabular}{|l|c|c|}
\cline { 2 - 3 } \multicolumn{1}{c|}{} & \multicolumn{1}{c|}{ Attentive } & Non-attentive \\
\hline Descriptive & Reflective introspection & $(?)$ \\
\hline Non-descriptive & Primitive introspection & Pre-reflective self-awareness \\
\hline
\end{tabular}

Table 1: Varieties of self-awareness

\subsection{Primitive introspection: a psychologically real phenomenon}

Consider an experience you are fairly familiar with, say, whisky-taste experience. ${ }^{11}$ When you introspectively attend to this experience, you can, almost immediately, think of it as a whisky-taste experience. Perhaps, if you are a whisky expert, you may think of that experience as, say, a peatywhisky-taste experience, or even as a Lagavulin-taste experience. This in virtue of your ability to recognize or classify your experience as a whisky-taste (peaty-whisky-taste, Lagavulin-taste) experience-ability that you possess, arguably, because you have already had whisky-taste (peatywhisky-taste, Lagavulin-taste) experiences before.

Now imagine, instead, that you have never tasted whisky before: you are now tasting it for the first time, without being told that what you are tasting is whisky. When you draw your

\footnotetext{
${ }^{9}$ See fn. 8.

${ }^{10}$ One proposal here might be that non-attentive but descriptive self-awareness is constituted by higher order thoughts à la Rosenthal (see e.g. Rosenthal 1997), i.e. mental states that are conceptual and propositional (that is, full-fledged thoughts) but unconscious. An immediate problem with this proposal, though, is that it is not straightforward how a mental state that is unconscious may constitute an awareness of one's experience.

${ }^{11}$ This does not imply that I expect most of my readers to be alcoholic, but that I imagine some of them to be fairly sophisticated whisky tasters.
} 
introspective attention to your taste experience, this time, you do not think of your experience as a whisky-taste experience (or as a peaty-whisky-taste, or as a Lagavulin-taste experience, for that matter). This, arguably, because you cannot classify that experience as a whisky-taste experience. Still, you can introspect the relevant experience: you can introspectively attend to it, even though you cannot classify it as an instance of any specific experience type.

To be sure, you may be able, in the latter case, to classify your experience as an instance of some experience type, say alcohol-taste experience, or, at the very least, as a taste experience. But what if you had never had any taste experience in your life before this one? True, it may require quite an effort of imagination, but you can surely conceive of a possible world in which you have never had any taste experience-say, because of a malfunction in your taste buds. In such a case, this whisky-taste experience is the very first taste experience you have ever had. Accordingly, there would be no experience-type at all (not even taste experience), such that you could classify your whisky-taste experience as an instance of it. Yet, you would still be able to attend to your experience and thereby introspect it. In this case, then, your introspective awareness is attentive but nondescriptive: it is an instance of what I have called primitive introspection.

Thought-experiments aside, there are at least three classes of cases, in our ordinary life, that feature the introspective phenomenon I call primitive introspection. The first class includes cases of experiences one has for the first time. In such cases, you do not recognize or classify the introspected experience because you cannot so classify or recognize it: you cannot recognize the experience because you have never instantiated that experience type. So, take any experience at the first time you had it: if you introspected it, your introspecting was an instance of primitive introspection. The first time you have an orgasm, for example, the experience you have is completely new to you: there is no already-encountered experience type under which you could classify the experience you are having. ${ }^{12}$ Nonetheless, you can certainly introspect your orgasm experience, even on the very first time you have it. Similarly, the first time you take a ride on a rollercoaster you have such an idiosyncratic experience that you cannot classify it as anything you have ever experienced before (or so it seemed to me the first time I took a rollercoaster ride). Once it is over, perhaps, you come to realize how exciting or amazing it was-you want to take another ride right away. However, at the time of the experience, the way you feel is so new to you that you are unable to classify it- not even as exciting or amazing. Nonetheless, you can certainly introspectively attend to your experience.

The second class features cases in which you can classify the experience (you do possess the right classificatory and recognitional abilities because you have already instantiated that experience type before), but you do not classify it because you do not want to- that is, because you decide not to classify the experience while introspecting. This is supposed to occur in some meditation practices. Some types of meditation require that you endeavor to 'observe' the goings-on within your mind without judging or describing them; leave any thought aside and observe what happens in your mind 'as it is', so to speak, and not as you would judge it to be upon classifying it under a familiar category. If you succeed, you engage in what I call primitive introspection. Something similar may have occurred to you even if you are not really a spiritual-meditative kind of person. You may

\footnotetext{
12 You may object that one who has an orgasm for the first time could at least classify it as a pleasure experience. However, first, it does not sound obvious to me that the first time one has an orgasm one would unhesitatingly classify it as a pleasurable experience (or as an unpleasant experience, for that matter). Secondly, if that does sound obvious to you, you can still imagine a person who has never had a pleasure experience before. Once they finally have one, arguably, there will be no previously encountered experience type under which they could classify it.
} 
have tried, sometimes, to introspect a certain experience of yours without forming any judgment about what that experience is - that is, by making an effort not to classify it as an instance of a familiar experience type. Perhaps, you may want to do this for aesthetic reasons: to contemplate and enjoy your experience better by attending to it in a non-classificatory or non-judgmental way.

In the third class we have cases where the subject not only can classify the experience but also does classify the experience. You will wonder: what makes these cases of primitive introspection? By definition, they seem to be cases of reflective (i.e. classificatory, or descriptive) introspection. Indeed, these cases do involve reflective introspection (or reflective self-awareness). Therefore, they are not cases of mere primitive introspection, for mere primitive introspection entails the absence of reflective introspection-it requires that the subject deploys no classificatory or recognitional ability at all. However, primitive introspection can co-occur with some reflective introspection and indeed ordinary-life introspection is often accompanied by some classification. Even in these cases, though, two kinds of introspection, a descriptive one and a non-descriptive one, can still be distinguished. For one thing, they can be distinguished conceptually: for any state of reflective introspection there is a possible state of primitive introspection the subject would have been in had they been unable to recognize and classify the introspected experience. More importantly, two kinds of introspection can be distinguished phenomenologically. Arguably, our introspective capacities outstrip our classificatory capacities. By reflective introspection one can only apprehend the phenomenal aspects which one can recognize and classify. But what one can apprehend by introspection exceeds what one can recognize and classify. So, it seems that even in cases in which one does classify the introspected experience one must also primitively introspect the experience. By primitive introspection, one can grasp the details of the phenomenology that are inaccessible to reflective introspection.

There are also theoretical reasons to admit the psychological reality of primitive introspection. In Giustina (forthcoming), I argue that doing so is required to make sense of our acquisition of certain introspective concepts. More specifically, denying the existence of primitive (non-classificatory and thereby non-conceptual) introspection entails an implausible, radical form of nativism about phenomenal concepts. For if all introspection were conceptual, no phenomenal concept could be acquired through introspection (on pain of circularity). Since most phenomenal concepts are acquired through introspection, if all introspection were conceptual, most phenomenal concepts would be innate. But this is quite implausible. So, if we are to avoid radical nativism about phenomenal concepts, we must accept the existence of non-classificatory introspection -i.e. primitive introspection. (See Giustina forthcoming for details.)

I take these considerations to provide good reasons for thinking that primitive introspection is a psychologically real phenomenon. To be sure, I do not take them to provide ultimate reasons, for which a fully developed argument, which I do not have the space to articulate here, would be needed.

\subsection{Varieties of self-awareness}

The interim conclusion of this section is that there are not only two, but at least three kinds of self-awareness: an attentive and descriptive one (reflective introspection), a non-attentive and nondescriptive one (pre-reflective self-awareness), and an attentive and non-descriptive one (primitive introspection). 
In the next section I will argue that, although all of them involve an apprehension of the experience they are an awareness of (they all provide the subject with information about the phenomenology of the relevant experience), the kind of apprehension each of them involves is different (because the amount of information each of them provides is different).

\section{VARIETIES OF NON-DESCRIPTIVE SELF-APPREHENSION}

\subsection{The epistemic dimension of primitive introspection and pre-reflective self-awareness}

Reflective introspection (or reflective self-awareness) has a quite straightforward epistemic import. When you attend to your experience, classify it under some familiar categories, and thereby form an introspective thought about it—provided you avoid gross mistakes—you learn something about your experience. Therefore, when you reflectively introspect, you grasp or apprehend something about the phenomenology of the experience that is the target of your introspective act. Such apprehension may be spelled out in terms of knowledge: by reflective introspection one can get some knowledge of one's current experience. Arguably, by reflective introspection one can hardly get a full grasp of the phenomenology (that is, acquire all knowledge there is to be acquired about the phenomenology of the relevant experience): there is likely something (or perhaps, sometimes, a lot) that fails to be captured by one's introspective thought. Still, reflective introspection may allow for a fair grasp of one's experience. ${ }^{13}$

Not only reflective introspection, I contend, but also pre-reflective self-awareness and primitive introspection have an epistemic dimension: they involve an apprehension of the phenomenology of the experience they are an awareness of.

It seems intuitive to think that, although pre-reflective, the self-awareness which accompanies each of our conscious experiences provides us with at least some knowledge about those experiences. If you are asked, say, what your (conscious) visual experience is right now, you are immediately in a position to reply, and you are in such a position just in virtue of your being (pre-reflectively) aware of your current visual experience. ${ }^{14}$ If you are asked what your (conscious) visual experience was one instant ago, even if you were not paying attention to the visual experience, you can nonetheless answer the question, arguably because, an instant ago, you were pre-reflectively aware of your visual experience. Moreover, the simple having (and thus being prereflectively aware) of an experience is sufficient for you to possibly remember such an experience at some time in the future (cf. Kriegel 2019), which implies that you have retained some information about the relevant experience. Relatedly, it enables you to possibly recognize future similar experiences: at the very least, arguably, the having of an experience $e$ puts you in a position to feel a "sense of familiarity" when you later encounter another experience which is similar to $e$ in some respect. Even such weak and somewhat vague "sense of familiarity" implies that you acquired at

\footnotetext{
13 Some philosophers (e.g. Dennett 1991; Schwitzgebel 2011) adopt a much more pessimistic stance on introspection's potentialities and argue that it is much less reliable a self-knowledge-acquisition process than several philosophers have thought. If they are right, then reflective introspection provides a poor grasp, or no grasp at all, of one's experience. Although it has the merit of reminding us of the limits of introspection, I believe that such criticism is too radical. However, arguing for this falls out of the scope of this paper. At any rate, it may be plausible to say, at least, that even if naïve introspection is much less reliable than it has often considered to be (Schwitzgebel 2008), trained (reflective) introspection may be a better candidate for providing the subject with a decent grasp of their experiences. ${ }_{14}$ As specified in footnotes 1 and 2, I am assuming here that having a conscious experience entails being prereflectively aware of it.
} 
least some information about the phenomenology of $e$ when you had (and thus were prereflectively aware of) it.

A further intuition which strengthens the pull of the epistemic significance of pre-reflective self-awareness comes from cases like the following. Imagine you have to explain what (physical) pain feels like to someone who has never felt any pain. Although you may well come up with a very detailed description of pain sensations, trying to make your interlocutor grasp what it is like to feel pain would be a hopeless enterprise. For no matter how sophisticated your description, your interlocutor will only get a grasp of what pain feels like upon having a pain sensation themselves. (Accordingly, although unpolite, the best-and indeed the only-way for you to 'convey' the relevant knowledge to your interlocutor is to provoke a pain sensation in them, say, by dealing them a good blow.) This strongly suggests that the mere having (and thus being prereflectively aware) of an experience provides the subject with some knowledge of that experience.

Primitive introspection also has a significant epistemic import. If being non-attentively (prereflectively) aware of an experience provides one with some knowledge of that experience, being attentively (although non-descriptively) aware of it may provide one with even deeper or fuller knowledge of it. Consider an analogy with perception. You put on some music while tidying up home. Although you are hearing it, you are not listening to the music: your attention is absorbed by deciding what to keep and what to throw away, reflecting upon how to rearrange stuff, and so on. Although you do not attend to it, you are aware of the music. This enables you to get at least a partial apprehension of the music: for instance, if I ask you what piece was on a second ago, you can tell me, or hum it to me. But, arguably, if you want to get a better or more detailed grasp of the music, to fully appreciate its complexity and richness, and retain a more vivid or accurate memory of it, peripheral auditory awareness is not sufficient: you need to attend to the music and listen to it carefully.

Similarly, attending to your experience enables you to grasp some details of its phenomenology which mere pre-reflective self-awareness does not make available the same way. Consider the following. You feel an unusual sensation in your back; notwithstanding it, you stay focused on your work. While your attention is absorbed by the work, the sensation lies on the fringe of your phenomenal field. You are still aware of it, although peripherally (pre-reflectively), and this provides you with at least some knowledge about it-for instance, you know that the sensation is still there (it has not disappeared). However, if you want to get a deeper grasp of the sensation and explore the fine details of its phenomenology, get a better knowledge of it, or retain a richer and more accurate memory of it, you need to shift your attention from the work to the sensation. Arguably, this occurs with any experience: when you want to know more about a certain experience of yours, you attend to it more closely.

Attention, thus, seems to make an epistemic difference. By attending to you experience you get, as it were, a different apprehension of its phenomenology. But what does, exactly, such difference consist in? Is it a qualitative or merely quantitative difference? Suggesting a way such epistemic difference may be spelled out is the purpose of the next subsections.

Before continuing, I should mention an immediate objection. At least sometimes, attending to one's experience affects its phenomenology. If you attend to a pain sensation of yours, the pain may become a bit more intense. Or if you attend to a certain emotional experience of yours, say, an experience of anger, it may occur that it cools down a bit- the anger phenomenology 
becomes a bit less intense. ${ }^{15}$ If introspective attention modifies the phenomenology, the objection goes, how can primitive introspection (or reflective introspection, for that matter), provide one with any (let alone a deeper, or fuller) apprehension or knowledge of it? I do not have the space, here, to develop a fully satisfactory reply. For the present purpose, however, I hope the following remarks suffice. If attention changes the phenomenology of the introspected experience, such change is (i) slight or minor (rather than major) and (ii) quantitative (rather than qualitative).

When you introspectively attend to your pain sensation, even if its intensity increases, it never increases dramatically: the intensity change is limited. More generally, when one focuses one's introspective attention on a current experience of one's (be it perceptual, algedonic, bodily, emotional, or what have you), even though this may affect the phenomenology, the phenomenal modification is modest and indeed, typically, barely significant (i). ${ }^{16}$

Moreover, a fundamental aspect of the phenomenology, that is, its qualitative component, is not affected by introspective attention (ii). There are at least two kinds of phenomenal property: qualitative and quantitative. Qualitative phenomenal properties are phenomenal features such as reddishness, painfulness, burning painfulness, stabbing painfulness, and so on. They define the qualitative aspect which characterizes each kind of experience: they are that which constitutes the difference between, say, an experience of redness, an experience of saxophone sound and an experience of stubbing pain. Quantitative phenomenal properties, on the other hand, are those in virtue of which qualitative phenomenal properties are modulated: for any quantitative phenomenal property $Q$, an experience $e$, that can have $Q$, can be more or less $Q$. Intensity is the paradigmatic example of quantitative phenomenal property. Other quantitative phenomenal properties include clarity and salience. The former may be spelled through the determinable/determinate distinction: ${ }^{17}$ as long as an experience can be phenomenally more or less determinate, its clarity or definiteness is a phenomenal property that can be quantified. As for the latter, an experience is more salient if it occupies the center of one's phenomenal field, less salient if it lies at the periphery. Typically, increase in salience is associated with the focusing of attention: what is attended to comes to occupy the center of one's phenomenal field and thereby becomes more salient. ${ }^{18}$

On my view, qualitative phenomenal properties are essential to an experience. For any experience $e$ and phenomenal property $F$ of $e, F$ is essential to $e$ iff, did $e$ not have $F$, it would not exist. Qualitative phenomenal properties are thus essential in that they make a certain experience the kind of experience it is. If this pain experience did not have the phenomenal property painfulness, it would not be a pain experience; therefore, it would not exist - another experience would be at its place. Quantitative phenomenal properties, instead, are not essential: experiences can change in quantitative phenomenal properties without ceasing to exist. When you stub your toe in the couch, the pain sensation you have is excruciating at first but, hopefully, it gradually decreases in intensity.

\footnotetext{
${ }^{15}$ Considerations like these underlie Brentano's argument that inner perception cannot become inner observation: "If someone is in a state in which he wants to observe his own anger raging within him, the anger must already be somewhat diminished, and so his original object of observation would have disappeared." (Brentano 1874: 30).

${ }^{16}$ Someone may object that, in some meditation practices, concentrating attention on a certain experience (e.g. pain) can make a big change to the phenomenology: it can make an experience disappear. My reply is that, if there are any such practices, they involve some further cognitive activities besides attention. The experience's disappearance, I would submit, is at least partly due to such accompanying activities rather than to the mere exercise of introspective attention.

${ }^{17}$ As for the determinable/determinate distinction consider the following: crimson is a determinate of red, which is a determinate of color; on the other hand, color is a determinable of red, which is a determinable of crimson.

${ }^{18}$ About the notion of phenomenal salience, and its relationship with attention, see Kriegel (2009b, Ch. 5) and Watzl (2017, Ch. 9).
} 
My contention is that the intensity-decrease process involves one and the same kind of experience (i.e. stubbing pain) which changes in intensity, rather than a succession of experiences of different kinds (very-intense-stubbing-pain, slightly-less-intense-stubbing-pain, even-less-intense-stubbingpain, and so on).

If this is right, then, even if attention modifies the phenomenology, such modification does not involve the essential aspects of the phenomenology. For what attention modifies are not the qualitative phenomenal properties: attention never turns, say a stubbing-pain experience into a saxophone-sound experience. All attention modifies are the quantitative phenomenal propertiesproperties such as intensity, clarity, and salience. Therefore, that introspective attention may affect the phenomenology of the introspected experience does not prevent the subject from getting substantial knowledge about it. ${ }^{19}$

\subsection{Information acquisition and personal-level availability}

I suggest that apprehension, that is, the epistemic dimension which characterizes different kinds of self-awareness (pre-reflective self-awareness, primitive introspection, and reflective introspection), should be spelled out in terms of information acquisition: by being aware of your current experience, you acquire information about its phenomenology. Acquired information may or may not also be personal-level available. The epistemic difference between different kinds of selfawareness, I argue, is due, on the one hand, to a difference in the quantity of information which is acquired and, on the other hand, to a difference in the quantity of acquired information which becomes personal-level available. In this section I explain the notions of information acquisition and personal-level availability at work in my account. In the next section I show how the two notions may help understand the epistemic differences between pre-reflective self-awareness and primitive introspection.

2.2.1. Information acquisition. Information is often characterized in terms of reduction of uncertainty, or exclusion of possibilities. ${ }^{20}$ The idea is that one acquires information about a certain state of affairs $s$ if one can rule out at least some possible worlds in which $\neg s .{ }^{21}$ This characterization provides us with a way to calculate the amount of information which is associated with a given event or state of affairs. It also enables us to evaluate whether information about a state of affairs is transmitted to a receiver and, if so, how much information gets transmitted. The amount of information associated with a given event or state of affairs is a function of the number of alternatives that the occurring of such event or state of affairs contributes to rule out: the more possibilities are excluded, the more information. If I draw a ball from a box containing 8 numbered balls, my telling you that the drawn ball is a 3 (suppose you are not watching the drawing and I tell you about the results through a written note) gives you more information about the ball-drawing event than my telling you that the drawn ball is an odd number: the former rules out seven

\footnotetext{
19 The argument proposed is admittedly sketchy. I have elaborated on these issues much more thoroughly in Giustina (2018, Ch. 4).

20 See Shannon (1948). This characterization became widespread in philosophical literature partly due to Fred Dretske's (1981) use of it in his theory of knowledge. The present section's treatment of the notion of information draws heavily on Dretske's.

21 Thank to Alfredo Tomasetta for suggesting this simple characterization of information acquisition to me.
} 
possibilities (that the ball is a 1 , a 2 , a 4 , a 5 , a 6 , a 7 , and an 8 ), the latter only four (that the ball is a 2 , a 4 , a 6 , and an 8 ).

In information transmission we distinguish the source $(s)$, which generates the information, and the receiver $(r)$, which receives the information. Both $s$ and $r$ have a certain amount of information associated with them, called $I(s)$ and $I(r)$ respectively. The information transmitted $I_{s}(r)$ is the information which is generated at $s$ and received by $r$-it is the overlap between $I(s)$ and $I(r)$. $I_{s}(r)$ is transmitted from $s$ to $r$ by a signal. In the example above, the ball-drawing event is the source and you are the receiver. $I(s)$ is that a 3 was drawn, $I(r)$ is that an odd number was drawn, and the note with "odd" written on it is the signal which transmits the information $I_{s}(r)$ from the drawing event to you.

As it emerges from the example, the amount of information transmitted by a signal partly depends on how finely-grained alternatives such a signal individuates. The signal transmitting the information that a 3 was drawn individuates alternatives in a finer-grained way than the signal transmitting the information that an odd number was drawn. Therefore, it transmits a greater amount of information.

There may be information which is generated at the source but does not get to the receiver. In the case just discussed, you get the information that the drawn number is odd, but not the information that the drawn number is a 3: you receive only part of the information generated by the drawing event. It may also be that there is more information associated with the receiver than is transmitted by the source. For instance, the word "odd" on my note for you may be written in a variety of different colors. Imagine it is written in red. To the event of your reading the red "odd" is associated not only the information that an odd number was drawn, but also that "odd" is written in red (it is not written in black, or in blue, or in green, or in any other color).

The amount of information associated with a given state of affairs is a function of the number of possibilities excluded by that state of affairs. However, exactly how many possibilities are excluded by a state of affairs is typically extremely hard, if possible at all, to calculate (Dretske 1981: 53). I said that the information associated with the 3-drawing event is that a 3 was drawn, which implies that the number of possibilities ruled out by such an event is seven (i.e. that the number is a 1, a 2, a 4, a 5, a 6, a 7, and an 8). In fact, the occurrence of that event rules out many more possibilities. For there are many more alternative ways the 3-drawing may occur. For example, the draw may be performed by a blindfolded child, or by a drawing machine, or by a dog, and so on. The ball with a " 3 " written on it may be of a variety of different colors. There may not even have been a draw in the first place, but, say, a horse race, or a football match. There is thus a huge amount of alternative ways things may have gone and therefore a huge amount of possibilities the occurrence of the 3 -drawing rules out. Calculating the exact amount of information associated with such an event is, therefore, extremely hard a task — to say the least.

This does not mean that our notion of information in terms of possibility exclusion is theoretically useless. For it can still, at the very least, play an important role in the analysis of information transmission. It enables us to compare the amount of information generated at a source and the amount of information associated with the receiver an thereby calculate whether the amount information transmitted is equal to or smaller than the amount of information generated (Dretske 1981: 54). Even though we have a hard time calculating the exact amount of information which is generated by the 3-drawing (because listing all the possible alternatives is just too hard a task), we can still draw important conclusions about how much of the information generated by that event is transmitted to you (the receiver). We can say that, if you come to know that a 3 was drawn, you 
acquire less information than is generated by the 3-drawing event (because that event also generates information about the color of the ball, how the drawing took place, and so on). We can also say that, if I come to know that a 3 was drawn, and you come to know that an odd number was drawn, you have received less information than I have about the relevant event.

2.2.2. Personal-level availability. That information is personal-level available, as I see it, means that it is available to the person as a whole - rather than merely to one or more of its subsystems (sub-personal states and processes)—for conscious and deliberate cognizing, reasoning, and action-guiding. ${ }^{22}$ Information which is processed by, say, our endocrine system, or by our immune system is typically not personal-level available. Information which is processed by our perceptual (visual, auditory, etc.) systems is only partly available to the whole person-plausibly, only the bits of information which reach the person's consciousness are personal-level available. That information is available for conscious and deliberate cognizing, reasoning, and action guiding means that it is the subject's disposal to be deployed (i.e. actively used and manipulated) by the subject, to carry out cognitive processes that are such that (i) the subject is aware of them (they do not occur unconsciously) and (ii) the subject carries them out actively, intentionally, and effortfully (they do not occur passively, automatically, or independently of the subject's will). To be sure, the subject does not need to actually engage in such cognitive processes for information to be personal-level available: it suffices that the subject is in a position to use it in this kind of processes.

When you see a tree (that is, when you have a veridical conscious visual experience of a tree), visual information about the tree is personal-level available to you. You can use such information to avoid the tree while walking (that is, to adjust your action to the tree's position); to try and recall from your botany classes what species it belongs to; to reason that, since it stands in a spot where wind may blow particularly fast during storms, cars parked nearby would be better moved away; and so on. To be sure, the visual experience through which the relevant information gets personal-level available to you depends on sub-personal information processing (light striking your retina, neural impulses sent to the visual cortex, and so on). Although it contributes to make visual information available, such unconscious sub-system information processing is not itself personal-level available.

\subsection{Information availability and apprehension in primitive introspection and pre-reflective self-awareness}

2.3.1. Non-descriptive self-awareness implies acquisition of some information. A phenomenally conscious experience $e$ generates a certain amount of information about its phenomenology (it is a source of information). Your awareness of $e$ is, in a sense, a receiver of information: it receives information about $e$ 's phenomenology. By being aware of $e$, you acquire some information about $e$ 's phenomenology.

As noted, that reflective introspection gives one at least a partial apprehension of one's current experience is relatively straightforward. Indeed, it seems natural to think that when you attend to your current experience, recognize it as an instance of an experience type you have already encountered and thereby form an introspective thought about your experience, you acquire some

\footnotetext{
${ }^{22}$ For a discussion of personal-level mental states see Kriegel (2012). Kriegel's own take on personal-level mental states is that they are states the subject is (at least minimally) aware of.
} 
information about the experience you introspect. For instance, you acquire the information that this experience is a hunger experience. Such information is personal-level available: you (the whole person) can use such information for conscious and deliberate cognizing and action-guiding. For instance, you may use information about your hunger experience to decide to prepare a pasta.

Also pre-reflective self-awareness and primitive introspection enable the subject to acquire information about their current conscious experience. As noted, one acquires information about a certain state of affairs $s$ if one can rule out at least some possible worlds in which $\neg s$. If we apply this to the case of information about experiences, we have that one acquires information about an experience $e$ if one can rule out at least some possible worlds in which $\neg e$. Now, it seems that both pre-reflective self-awareness and primitive introspection enable one to rule out at least some possible worlds in which $\neg e$.

For one thing, if you are (pre-reflectively or primitive-introspectively) aware of $e$, you can rule out the possible worlds in which there is no experience at all. For, were there no experience, you could not be in the relevant state of awareness directed toward $e$. Denying this would imply that it is possible that it (pre-reflectively or primitive-introspectively) seems to one that one has an experience although one is not having any experience. But this strikes me as simply inconceivable. ${ }^{23}$ I may well be wrong about what phenomenal features my current experience has. But I cannot be wrong about there being an experience. Therefore, when one is aware of $e$, one acquires, at the very least, the information that an experience is present- that there is an experience rather than no experience.

For another thing, being (pre-reflectively or primitive-introspectively) aware of $e$ enables one to rule out the possible worlds in which there is an experience which is incompatible with $e$. For instance, your being aware of a homogeneously greenish visual experience enables you to rule out the possible worlds in which you have a visual experience as of any other color.

So, at the very least, the epistemic import of pre-reflective self-awareness and primitive introspection consists in enabling the subject to rule out the possible worlds in which (i) no experience is present or (ii) there is an experience that is incompatible with the experience the subject is actually aware of. However, on my view, these are not the only bits of information one may acquire by being (pre-reflectively or primitive-introspectively) aware of an experience.

2.3.2. Non-descriptive self-awareness implies acquisition of the maximal amount of information about e's phenomenology. As pointed out above, the amount of information transmitted by a signal partly depends on how finely-grained alternatives such a signal individuates. Let us apply this to reflective introspection first. When you reflectively introspect that $e$ is $F$, the amount of information you acquire by so introspecting partly depends on how finely-grained $F$ individuates $e$ 's phenomenology. It therefore depends on $F$ s degree of determinacy: the more determinate, the more information. Take the following phenomenal properties: phenomenal crimson, phenomenal red, and phenomenal color. Straightforwardly, the first is the most specific (the most determinate), the last is the most generic (the less determinate). The three properties bear a determinable-

\footnotetext{
${ }^{23}$ To be sure, not all philosophers share my intuition on this point. Defenders of so-called illusionism about phenomenal consciousness, for example, argue that it is always the case that it seems to one that one has an experience while one is having no experience at all (see e.g. Dennett 1988, Frankish 2016, and Kammerer 2016). Arguing against illusionism exceeds the scope of this paper. However, since I believe that illusionism is false, I take incompatibility with illusionism not to constitute a real threat to my account.
} 
determinate relationship to each other: phenomenal color is a determinable of phenomenal red, which is a determinable of phenomenal crimson; phenomenal crimson is a determinate of phenomenal red, which is a determinate of phenomenal color ${ }^{24}$ When you come to know that $e$ is phenomenal-red, you can thereby rule out the possible worlds in which $e$ is not phenomenal-red, i.e. the possible worlds in which $e$ is olfactory, pain, anger, phenomenal-blue, phenomenal-green, phenomenal-yellow, and so on and so forth. When you come to know that $e$ is phenomenal-colored, you can still rule out the possible worlds in which $e$ is olfactory, pain, anger, and so on (i.e. the possible worlds in which $e$ is not phenomenal-colored); however, in this case you cannot also rule out the possible worlds in which $e$ is phenomenal-blue, phenomenal-green, phenomenal-yellow, and so on, for your coming to know that $e$ is phenomenal-colored does not provide you with information about what particular phenomenal color $e$ is. Since, recall, the amount of information acquired is a function of the number of possibilities excluded, when you come to know that $e$ is phenomenal-colored, you acquire less information than when you come to know that $e$ is phenomenal-red. When, instead, you come to know that $e$ is phenomenal-crimson, you can rule out not only the possible worlds in which $e$ is olfactory, pain, anger, phenomenal-blue, phenomenalgreen, phenomenal-yellow, and so on (as in the case where you come to know that $e$ is phenomenalred); in this case, you can, in addition, rule out the possible worlds in which $e$ is phenomenal-scarlet, phenomenal-vermilion, phenomenal-carmine, phenomenal-cherry, and so on. Therefore, when you come to know that $e$ is phenomenal-crimson, you acquire more information than when you come to know that $e$ is phenomenal-red (and, a fortiori, more information than when you come to know that $e$ is phenomenal-colored), for you can rule out a greater number of possibilities.

In non-descriptive (pre-reflective or primitive-introspective) self-awareness, the experience one is aware of is not classified as an instance of any more general experience type: one is aware of one's experience as it is, so to speak, rather than as an instance of a more general or coarsergrained experience type. In non-descriptive self-awareness, therefore, possibilities are individuated in a maximally fine-grained way: the possible alternatives, that is, ways $e$ 's phenomenology may be, are individuated at the maximal level of determinacy. Accordingly, non-descriptive self-awareness enables the subject to rule out many more possible worlds than reflective introspection does. When, for instance, you are non-descriptively aware of your phenomenal-crimson experience, you can rule out not only the possible worlds in which your experience is phenomenal-scarlet, phenomenal-vermilion, phenomenal-carmine, phenomenal-cherry, and so on. In this case you can rule out many more worlds in which your experience is just slightly phenomenally different from how it is, say, worlds in which it is of a slightly different shade, or slightly phenomenally brighter, or slightly phenomenally more intense, and so on.

Being non-descriptively aware of $e$ therefore enables the subject to exclude the highest number of possible phenomenologies, that the subject may instantiate, which are different from the actual phenomenology of $e$. To be sure, this does not yet entail that non-descriptive selfawareness allows for acquisition of all the information about $e$ 's phenomenology that is generated by e's occurrence..$^{25}$ All I claim, here, is that non-descriptive self-awareness allows for acquisition of the maximal amount of such information: there is no mental state or process that allows for acquisition of more information about $e$ 's phenomenology.

\footnotetext{
${ }^{24}$ Of course, by transitivity, phenomenal color is also a determinable of phenomenal crimson and phenomenal crimson is also a determinate of phenomenal color.

25 Although I believe it does, arguing for this falls out of the scope of this paper.
} 
2.3.3. Only primitive introspection makes all acquired information personal-level available. So, both being prereflective aware of $e$ and primitively introspecting $e$ enable the subject to acquire the maximal amount of information about $e$ 's phenomenology: both potentially allow for the subtlest phenomenological distinctions. However, only primitive introspection also makes all such information personal-level available, because only primitive introspection puts the subject in a position to deploy all such information for cognition, reasoning, and action guidance. To be sure, I do not claim that pre-reflective self-awareness makes none of such information personal-level available. Rather, my claim concerns the quantity of information that gets personal-level available: differently from primitive introspection, pre-reflective self-awareness makes only some of the information about the phenomenology personal-level available.

This may become clearer if we compare the quantity of information that is retained by the subject after being merely pre-reflectively aware of an experience, on the one hand, and after primitively introspecting it, on the other hand. Being pre-reflectively aware of an experience of yours, say of a whisky-taste experience, while your attention is mostly absorbed by a passionate conversation with a friend, enables you to recollect some information about it. Arguably, it enables you to recall that the experience you were having was tasting whisky. Perhaps it also enables you to recall some finer-grained features of the phenomenology (e.g. that the whisky was a peaty one). Whatever information pre-reflective self-awareness enables you to recall, introspectively attending to your experience enables you to recollect more information later on. If, instead of being absorbed by a conversation, your attention is entirely focused on the whisky-taste experience, you get access to many more details of the taste phenomenology: you can personal-level discriminate finergrained phenomenological features. Accordingly, you will then be able to retain more information about the phenomenology of the experience. So, for instance, you will be more likely to recognize a whisky-taste experience of the same kind if you primitively introspected it, than if you were merely pre-reflectively self-aware of it. ${ }^{26}$

The same point may be made in a slightly different way. If you are an aspiring whisky expert, arguably, you want to acquire a great number of fine-grained whisky-taste-associated concepts, i.e., concepts that enable you to distinguish and recognize taste experiences associated with a great number of different types of whisky. To achieve this result, for any whisky-taste experience you want to acquire a concept of, you need to gain and store information about its phenomenology. Quite obviously, merely drinking a large variety of whiskies, say, while conversing with friends (and thereby being merely pre-reflectively aware of each whisky-taste experience) is not sufficient to accomplish the task. The information-gaining-and-storing process required for

\footnotetext{
${ }^{26}$ It may be objected that, for at least some kinds of experience, this does not hold. If, for instance, one starts introspecting one's anger soon after its onset, one may later have less ability to recall how the anger was originally, i.e. before being introspected: if one had let oneself be merely pre-reflectively aware of it a little longer, the objection goes, one would be better able to recall its original quality. (I owe this objection to Uriah Kriegel.) However, for one thing, primitive introspection is supposed to provide one with information about the experience as it is while being primitively introspected, rather than as it was before being primitively introspected. Even if, upon being primitively introspected, the anger undergoes a phenomenal modification, the fact remains that the quantity of information retained will still be greater when the anger is primitively introspected then when it is merely experienced. Moreover, as noted, the relevant change is not dramatic: it is small and merely quantitative. Therefore, it seems to me that even in the case of anger, primitively introspection enables recollection of more information than mere pre-reflective selfawareness.
} 
whisky-taste fine-grained concept formation is an effortful and deliberate activity, which requires one to focus one's attention on each whisky-taste experience.

The quantity of information that gets personal-level available depends on the amount of attentional resources that are dedicated to the relevant experience: the more attentional resources, the more information. If you want to get more information about the music piece you are listening to, you need listen to it more attentively. Analogously, if you want to get more information about a current experience of yours, you need to attend to it more closely. Therefore, attention modulates the quantity of information that gets at the personal level. If you devote the maximal amount of attentional resources to your experience, then the maximal amount of information about its phenomenology becomes personal-level available. Therefore, if, when you primitively introspect your experience $e$, all your attentional resources are concentrated on $e$, all the information about $e$ 's phenomenology which is acquired through your state of self-awareness is also available for personal level cognizing, reasoning and action-guiding. ${ }^{27}$

\subsection{Varieties of self-apprehension}

The notions of information acquisition and personal-level availability help analyze not only the epistemic difference between pre-reflective self-awareness and primitive introspection, but also that between these forms of non-descriptive self-awareness and reflective introspection. As noted, reflective introspection involving classification, the phenomenological discriminations it allows for are always coarser-grained than those enabled by pre-reflective self-awareness and primitive introspection. Since, recall, coarser-grained selection of possibilities results in loss of information, the amount of information acquired through reflective introspection is always smaller than the amount of information acquired through pre-reflective self-awareness or primitive introspection. Therefore, the main epistemic difference between the non-descriptive forms of self-awareness and reflective introspection is that the former but not the latter allow for acquisition of the maximal amount of information about the phenomenology of the relevant experience.

However, since reflective introspection, like primitive introspection, involves focusing one's attention on one's experience, all the information which is acquired becomes personal-level available. When you are reflective-introspectively aware your current taste experience as a peaty-

27 Incidentally but interestingly, this seems to square well with some recently proposed interpretations of the relationship between inner perception and inner observation in Brentano's thought. Johannes Brandl (2013) has argued that inner perception and inner observation should not be considered as two distinct faculties, but rather one single faculty yielding different epistemic results depending on whether the relevant experience is taken as a primary object (in inner observation) or a secondary object (in inner perception). When it is taken as a secondary object in inner perception, the subject's awareness of it is confused or indistinct, when it is taken as a primary object in inner observation, the subject's awareness of it is clear or distinct. The distinction between clear or distinct and confused or indistinct is characterized in terms of discrimination: when one inner perceives (i.e. is pre-reflectively aware of) one's experience $e$, one's awareness of $e$ is confused in that one cannot discriminate the details of $e$ 's phenomenology; when one inner observes (i.e. introspectively attends to) $e$, instead, one can make subtler phenomenological discriminations. Although he does not focus on its relationship to inner observation, Arnaud Dewalque (2018) makes interesting remarks about the epistemic features of inner perception. He points at a distinction between two different epistemic notions which has often been overlooked (especially by critics of Brentano's theory): evidence on the one hand, and clearness or distinctness on the other. The former is characterized in terms of indubitability, the latter in terms of discriminability. Dewalque then argues that Brentano's thesis is that inner perception is evident, but not that inner perception is clear or distinct. This is consistent with the intuition that although being pre-reflectively aware of an experience $e$ makes $e$ 's existence indubitable, it does not allow for personal-level discrimination of the finer details of $e$ 's phenomenology. 
whisky-taste experience, you lose some information about the taste phenomenology-its details are not fully captured by the concept PEATY-WHISKY-TASTE EXPERIENCE. Nonetheless, all the information which is so introspectively acquired is available to you to be used in cognition, reasoning, and action guidance.

Therefore, the epistemological differences between pre-reflective self-awareness, primitive introspection, and reflective introspection may be neatly analyzed by appeal to the way the presence or absence of classification, on the one hand, and the amount of introspective attention, on the other hand, modulate the flux of information from the experience to the experiencer (Figure 1). More specifically, the presence or absence of classification modulates the amount of information which is acquired (i.e. the amount of information which is transmitted from the experience to the awareness of the experience): absence of classification implies acquisition of the maximal amount of information; when classification is present, the coarser-grained the classification, the smaller the amount of acquired information. On the other hand, attention modulates the amount of information that gets personal-level available: the more attentional resources are devoted to the experience, the more information about its phenomenology becomes personal-level available; if all attentional resources are devoted to the experience, then all the acquired information becomes personal-level available.

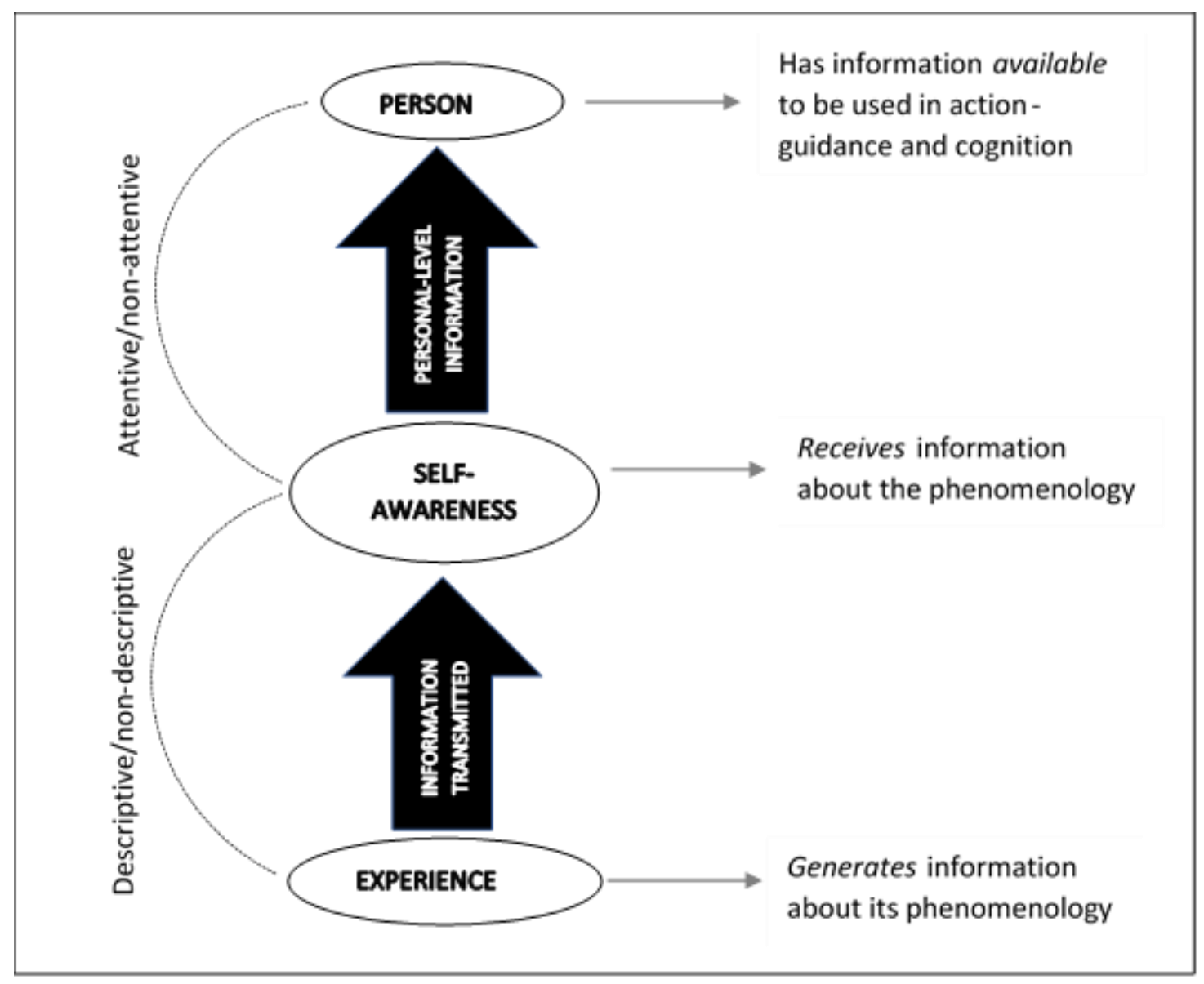

Figure 1: The information flux in self-awareness and how it may be modulated by descriptiveness and attentiveness 
As it emerges, only primitive introspection makes the maximal amount of information personallevel available. For in pre-reflective self-awareness, although the maximal amount of information is acquired (due to absence of classification), not all such information becomes personal-level available (due to the scarce amount of attentional resources dedicated to the experience). In reflective introspection, on the other hand, although all information acquired gets personal level available (due to the focusing of attention on the experience), the amount of information acquired is never maximal (due to the presence of classification). By contrast, primitive introspection, by being non-classificatory it allows for acquisition of the maximal amount of information; by being attentive it makes all acquired information personal-level available. Therefore, it makes the maximal amount of information personal-level available. Table 2 summarizes the epistemic differences between pre-reflective self-awareness, primitive introspection, and reflective introspection.

\begin{tabular}{|l|c|c|}
\cline { 2 - 3 } \multicolumn{1}{c|}{} & Max amount of info generated is acquired & All info acquired is p.-l. available \\
\hline Pre-reflective self-awareness & $\checkmark$ & $\mathbf{x}$ \\
\hline Primitive introspection & $\checkmark$ & $\checkmark$ \\
\hline Reflective introspection & $\mathbf{x}$ & $\checkmark$ \\
\hline
\end{tabular}

Table 2: Varieties of self-apprehension

\section{CONCLUSION}

In this paper, I have pointed at an introspective phenomenon that recent debates on pre-reflective self-awareness seem to have overlooked. By isolating two features associated with the notion of reflectiveness - attentiveness and descriptiveness-I have tried to show that not only two, but three kinds of self-awareness should be distinguished. Since attention and classification are separable (one may occur independently of the other), besides non-attentive and non-classificatory selfawareness (i.e. pre-reflective self-awareness) and attentive and classificatory self-awareness (i.e. reflective introspection), there is a third kind of self-awareness, what I have called primitive introspection, which is non-classificatory but attentive.

Pre-reflective self-awareness and primitive introspection differ in epistemic import. I have argued that such epistemic difference may be analyzed in terms of amount of acquired information that becomes personal-level available. Whereas both pre-reflective self-awareness and primitive introspection allow for acquisition of the maximal amount of information about the phenomenology of the experience they are awareness of, only primitive introspection also makes all such information personal-level available-pre-reflective self-awareness makes only part of such information personal-level available.

The notions of information acquisition and personal-level availability provide a nice framework for the more general analysis of the epistemic differences between all three kinds of self-awareness (pre-reflective self-awareness, primitive introspection, and reflective introspection). The upshot is the following. Being attentive and classificatory, reflective introspection makes all the information acquired personal-level available, but the amount of information it enables to acquire is never maximal. Being non-classificatory, pre-reflective self-awareness allows for acquisition of the maximal amount of information; however, being non-attentive, it does not make 
all such information personal-level available. Primitive introspection, non-classificatory but attentive, is the only kind of self-awareness which makes the maximal amount of information about the phenomenology of the relevant experience personal-level available. ${ }^{28}$

\footnotetext{
${ }^{28}$ This work was supported by the French National Research Agency's grants ANR-10-IDEX-0001-02 PSL and ANR10-LABX-0087 IEC. It was presented in the "Introspection and Self-Awareness" conference in Liège and in the "The Subjectivity of Experience" workshop in Mexico City. I am grateful to the audiences there, in particular to Miguel Ángel Sebastián, Paloma Atencia-Linares, Davide Bordini, Bertille De Vlieger, Arnaud Dewalque, Charlotte Gauvry, Andrea Guerrero, François Kammerer, Andrew Lee, Giovanni Merlo, Johnathan Mitchell, Azul Santibañez Méndez, Pedro Stepanenko Gutiérrez, Josh Weisberg, and Ken Williford. I am especially grateful to Uriah Kriegel for discussing at length this paper's issues with me and for his thorough comments on a previous draft.
} 


\section{REFERENCES}

Armstrong, David M. 1968. A Materialist Theory of the Mind. New York: Humanities Press.

Block, Ned. 1995. "On a Confusion About a Function of Consciousness." Behavioral and Brain Sciences 18 (2): 227-247.

Brandl, Johannes L. 2013. “What Is Pre-Reflective Self-Awareness? Brentano's Theory of Inner Consciousness Revisited." In Themes from Brentano, edited by Denis Fisette and Guillaume Fréchette, 41-65. Amsterdam; New York: Rodopi.

Brentano, Franz. 1874. Psychology from an Empirical Standpoint. Edited by Linda L. McAlister. Translated by Antos C. Rancurello, Dailey B. Terrell, and Linda L. McAlister. London; New York: Routledge.

Caston, Victor. 2002. "Aristotle on Consciousness." Mind 111 (444): 751-815.

Chalmers, David J. 2004. "The Representational Character of Experience." In The Future for Philosophy, edited by Brian Leiter, 153-181. Oxford: Oxford University Press.

Cramer, Konrad. 1974. “'Erlebnis': Thesen Zu Hegels Theorie Des Selbstbewußtseins Mit Rücksicht Auf Die Aporien Eines Grundbegriffs Nachhegelscher Philosophie.” In Stuttgarter Hegel-Tage 1970, edited by Hans-Georg Gadamer, Beiheft 11:537-603. Bonn: Hegel-Studien.

Dennett, Daniel C. 1988. "Quining Qualia." In Consciousness in Contemporary Science, edited by Anthony J. Marcel and Edoardo Bisiach. Oxford: Oxford University Press. 1991. Consciousness Explained. Boston: Little, Brown, and Co.

Dewalque, Arnaud. 2018. “Conscience Interne et Connaissance de Soi. Descartes et Brentano.” In Descartes et La Phénoménologie. Paris: Hermann.

Dretske, Fred. 1981. Knowledge and the Flow of Information. Cambridge, Mass: MIT Press. 1995. Naturalizing the Mind. Cambridge, MA: MIT Press.

Frank, Manfred. 1986. Die Unhintergebbarkeit von Individualität. Frankfurt am Main: Suhrkamp. - 1991. Selbstbewnubtsein Und Selbsterkenntnis. Stuttgart: Reclam.

Frankish, Keith. 2016. "Illusionism as a Theory of Consciousness." Journal of Consciousness Studies 23 (11-12): 11-39.

Gallagher, Shaun. 2005. How the Body Shapes the Mind. Oxford: Oxford University Press.

Giustina, Anna. Forthcoming. "Introspection without Judgment." Erkenntnis.

—. 2018. "Primitive Introspection." PhD Dissertation, Paris: ENS, PSL.

Goldman, Alvin I. 1970. A Theory of Action. Princeton: Princeton University Press.

Henrich, Dieter. 1970. "Selbstbewußtsein, Kritische Einleitung in Eine Theorie." In Hermeneutik Und Dialektik, edited by Rüdiger Bubner, Konrad Cramer, and Reiner Wiehl, 257-84. Tübingen: Mohr.

1982. Fluchtlinien. Frankfurt am Main: Suhrkamp.

Horgan, Terence, and Uriah Kriegel. 2007. "Phenomenal Epistemology: What Is Consciousness That We May Know It so Well?” Philosophical Issues 17 (1): 123-144.

Horgan, Terence, John Tienson, and George Graham. 2006. "Internal-World Skepticism and the Self-Presentational Nature of Phenomenal Consciousness." In Self-Representational Approaches to Consciousness, edited by Kriegel Uriah and Kenneth Williford, 41-61. Cambridge, Mass.: Bradford Books/MIT Press.

Husserl, Edmund. 1983. Ideas Pertaining to a Pure Phenomenology and to a Phenomenological Philosophy: First Book: General Introduction to a Pure Phenomenology. The Hague; Boston; Lancaster: Kluwer Academic Publishers.

. 1991. On the Phenomenology of the Consciousness of Internal Time (1893-1917). Husserliana: Edmund Husserl - Collected Works. Dodrecht; Boston; London: Kluwer Academic Publishers.

. 2008. Introduction to Logic and Theory of Knowledge: Lectures 1906-07. Edited by Ullrich Melle. Translated by Claire Ortiz Hill. Dordrecht: Springer. 
Kammerer, François. 2016. "The Hardest Aspect of the Illusion Problem--and How to Solve It." Journal of Consciousness Studies 23 (11-12): 124-39.

Kentridge, R. W., C. A. Heywood, and L. Weiskrantz. 1999. "Attention without Awareness in Blindsight." Proceedings of the Royal Society of London B: Biological Sciences 266 (1430): 1805-11.

Kriegel, Uriah. 2002. "PANIC Theory and the Prospects for a Representational Theory of Phenomenal Consciousness." Philosophical Psychology 15 (1): 55-64.

. 2009a. "Self-Representationalism and Phenomenology." Philosophical Studies 143 (3): 357381.

2009b. Subjective Consciousness: A Self-Representational Theory. Oxford: Oxford University Press.

2012. "Personal-Level Representation." Protosociology 28: 77-114.

2018. Brentano's Philosophical System: Mind, Being, Value. Oxford: Oxford University Press.

2019. "Dignga's Argument for the Awareness Principle: An Analytic Refinement."

Philosophy East and West 69: 144-56.

Kriegel, Uriah, and Kenneth Williford. 2006. Self-Representational Approaches to Consciousness. Cambridge, Mass.: MIT Press.

Lévinas, Emmanuel. 1999. Alterity and Transcendence. New York: Columbia University Press.

Lycan, William G. 1996. Consciousness and Experience. Cambridge, MA: MIT Press.

Merleau-Ponty, Maurice. 1976. Phénoménologie de la perception. Paris: Gallimard.

Pothast, Ulrich. 1971. Über Einige Fragen Der Selbstberiehung. Frankfurt am Main: Vittorio Klostermann.

Rosenthal, David M. 1997. “A Theory of Consciousness.” In The Nature of Consciousness: Philosophical Debates, edited by Ned Block, Owen J. Flanagan, and Güven Güzeldere, 729-53. Cambridge, MA: MIT Press.

Sartre, Jean-Paul. 1936. "La Transcendance de l'ego.” Les Recherches Philosophiques 6: 85-123.

. 1943. L'être et Le Néant. Essai d'ontologie Phénoménologique. Paris: Gallimard.

Schwitzgebel, Eric. 2008. "The Unreliability of Naive Introspection." Philosophical Review 117 (2): 245-273.

- 2011. Perplexities of Consciousness. Cambridge, MA: MIT Press.

Shannon, Claude E. 1948. "A Mathematical Theory of Communication.” Bell System Technical Journal 27 (3): 379-423.

Siewert, Charles. 2004. “Is Experience Transparent?” Philosophical Studies 117 (1-2): 15-41.

Tye, Michael. 1995. Ten Problems of Consciousness: A Representational Theory of the Phenomenal Mind. Cambridge, MA: MIT Press.

Watzl, Sebastian. 2017. Structuring Mind. The Nature of Attention and How It Shapes Consciousness. Oxford: Oxford University Press.

Williford, Kenneth. 2006. "The Self-Representational Structure of Consciousness." In SelfRepresentational Approaches to Consciousness, edited by Uriah Kriegel and Kenneth Williford, 111-42. Cambridge, Mass.: MIT Press.

. 2015. "Degrees of Self-Presence: Rehabilitating Sartre's Accounts of Pre-Reflective SelfConsciousness and Reflection." In Pre-Reflective Consciousness: Early Sartre in the Context of Contemporary Philosophy of Mind, edited by Sofia Miguens, Gerhard Preyer, and Clara Morando Bravo, 66-100. London; New York: Routledge.

Zahavi, Dan. 1999. Self-Awareness and Alterity: A Phenomenological Investigation. Evanston, Ill: Northwestern University Press.

2005. Subjectivity and Selfhood: Investigating the First-Person Perspective. Cambridge, Mass.: Bradford Books/MIT Press.

. 2007. "The Heidelberg School and the Limits of Reflection." In Consciousness: From Perception to Reflection in the History of Philosophy, edited by Sara Heinämaa, Vili Lähteenmäki, and Pauliina Remes, 267-85. Studies In The History Of Philosophy Of Mind. Dordrecht: Springer Netherlands. 